\title{
ANTENNA CALIBRATION MODELS IN HEIGHT DETERMINATIONS IN ASG-EUPOS' POZGEO-D SERVICE - A CASE STUDY
}

\author{
Karol Dawidowicz \\ University of Warmia and Mazury \\ Institute of Geodesy \\ ul. Oczapowskiego 1, 10-950 Olsztyn, Poland \\ e-mail: karol.dawidowicz@uwm.edu.pl
}

\begin{abstract}
GNSS observations in a network of permanent stations are a complex systems which offer both post-processing and corrections sent in real-time. In Poland such a system, known as the Polish Active Geodetic Network (ASG-EUPOS), has been in operation since June 2008. The GNSS development forces also continuous modernization of ASG-EUPOS (e.g.: GPS/GLONASS receivers mounting, ASG+ project) which aims to improve the accuracy of position determination. One of the factors limiting the accuracy (especially the vertical component) is antenna phase center variations (PCV) problem.

PCV problem is resolved using the antenna calibration process. As a result, antenna phase center corrections models (PCC) are created. So far three methods have been developed to determine GNSS antenna PCV. For this reason and because of some problems in introducing of absolute models at present we can speak of three models of receiver antennas PCV (so called: relative, absolute converted and absolute).

The aim of this paper was to study the height differences caused by using different calibration models in GNSS observation processing done in the ASG-EUPOS POZGEO-D service. The analysis was done using 3 days of GNSS data, collected with four different receivers and antennas, divided by one hour observation sessions. The results of the calculations show that switching between PCV models may have a visible effect on height determination, particularly in high accuracy applications.
\end{abstract}

Keywords: ASG-EUPOS, POZGEO-D, GNSS antenna, phase center variations.

\section{INTRODUCTION}

In the GNSS structure are available so-called augmentation systems. These augmentation systems have been classified into two groups: Space Based Augmentation Systems (SBAS) and Ground Based Augmentation Systems (GBAS). GBAS systems can be divided by the area of operation into: global ground support systems (e.g. IGS - International GNSS Service), continental ground support systems (e.g. EPN or AUSPOS), national or regional ground support systems (e.g. ASG-EUPOS, CORS, SAPOS, SWEPOS). Another example of GBAS are so-called Local Area Augmentation Systems (LAAS), whose task is provide accuracy and integrity information in a local area, e.g. at an airport (Bosy et al., 2008; Figurski et al., 2009; Snay and Soler, 2009). 
ASG-EUPOS is a Polish GNSS Ground Based Augmentation System (Bosy et al., 2008). The name ASG-EUPOS stands for Aktywna Sieć Geodezyjna - European Position Determination System. Actually, (05.2012) ASG-EUPOS consists of 99 polish and 22 foreign stations (Figure 1).

ASG-EUPOS offers two post-processing and three real-time services. Real-time services are based on DGNSS (Differential GNSS) or RTK (Real-Time Kinematics) techniques. Depending on the surveying method and hardware capabilities, the precision of real-time services in ASG-EUPOS varies between $3 \mathrm{~m}$ and $3 \mathrm{~cm}$. It is well-known that the measurements performed in real time usually characterized lower accuracy than static measurements - the post-processing services are provided for users who conduct static surveys in the field and demand the highest precision results (Table 1).

Table 1. ASG-EUPOS post-processing services

\begin{tabular}{|c|c|c|c|c|}
\hline Service name & Survey method & $\begin{array}{c}\text { Data } \\
\text { access }\end{array}$ & $\begin{array}{c}\text { Estimated } \\
\text { precision }\end{array}$ & $\begin{array}{c}\text { Minimum hardware } \\
\text { requirements }\end{array}$ \\
\hline POZGEO & static & Internet & $0.01-0.10 \mathrm{~m}$ & L1 GNSS receiver \\
\cline { 1 - 2 } POZGEO-D & static / kinematic & & \\
\hline
\end{tabular}

The POZGEO service enables a user to send observation files in the RINEX format in order to receive automatically calculated coordinates of the measured points. The result in the form of a report are available for downloading via the ASG-EUPOS website. Post-processing of the uploaded observations and determination of the point's coordinates are made independently in reference to the six nearest system station. Because of the relatively long distances between stations $(\sim 70 \mathrm{~km})$ and the automation of the calculation process, obtaining high accuracy requires long observation sessions.

The POZGEO-D service is meant for users who utilize their own software to process GNSS observations. In this approach, users can download ASG-EUPOS reference stations observation files from the ASG-EUPOS website for their own processing. Using the POZGEO-D service makes possible to obtain higher accuracy from shorter observational sessions. It should be noted although that it requires some knowledge of GNSS observation processing.

The point in space where the GNSS signal is received is called the electrical antenna phase center. The actual location of that point, however, varies depending on the direction of the incoming GNSS signal, i.e. on the observed elevation angle and azimuth to the satellite. A review of the antenna phase center variations problem can be found, e.g. in Braun et al. (1993), Dawidowicz (2010), Geiger (1998), Rocken (1992), Schmid et al. (2005).

Antenna PCV can achieve an amplitude of several centimeters. When the same type of antennae are used in relative measurement, the PCV will be reduced, particularly over short baselines. When different antennas are used, even on short baselines, ignoring these PCV can lead to serious (up to $10 \mathrm{~cm}$ ) vertical errors (Mader, 1999; Rothacher and Mader, 1996). The size of this error depends on the differences in the antenna PCV characteristics.

Actually three main methods have been distinguished to determine GNSS antenna phase center variations:

- relative field calibrations,

- anechoic chamber measurements,

- absolute field calibrations.

Relative field calibration is a technique in which the PCV of one antenna is determined relative to another, reference antenna (Mader, 1999; Rothacher and Mader, 1996). In this method, only the differences in the phase center behavior between the two antennas are 
determined. This method is based on the assumption that the reference antenna (AOAD/M_T) has not PCV.

In anechoic chamber measurements, an absolute antenna PCV is obtained. This method is based on analyzing how the phase of an artificial GNSS signal is changed when the antenna, put into an anechoic chamber, is rotated and tilted. The main advantage of this method is that it guarantees very high efficiency and the same conditions for all calibrated antennas. The disadvantage is that the test signal is not the same as the real GNSS signals (Görres et al., 2006; Rothacher, 2001; Zeimetz and Kuhlman, 2008).

The absolute field calibration method is based on the existence of a perfectly calibrated robot on which the test antenna is located. The robot rotates and tilts the test antenna in different axes and, as a result, the phase center offsets (PCOs) and PCVs are estimated. The advantage of the absolute field calibration is that the real GNSS signals are tracked in the natural field environment (Falko et al., 1998; Rothacher, 2001; Schmid et al, 2005).

Despite the clear benefits of the absolute calibrations, the International GNSS Service (IGS) did not decide to accept these methods as official until 2006. This was due to the fact that the use of absolute antenna PCC caused an unreasonable scale error (15 ppb) and, as a result, a height change of 5 to $10 \mathrm{~cm}$. In the end it was found that not only the receiver, but also the satellite antenna, showed phase center variations. These variations were the reason for the scale factor that results in global GNSS solutions, when the absolute phase center patterns are applied (Rothacher, 2001; Schmid and Rothacher, 2003; Zhu et al., 2003).

The satellite PCO and PCV estimated by GeoForschungsZentrum and the Technical University of Munich were averaged and so the final antenna PCC for each satellite was created. When the relative antenna calibration method was used, only for the GPS satellites (blocks II and IIA) the PCO were known and used (the so-called "standard" IGS antenna offsets for GPS satellites). But standard IGS antenna offsets had doubtful accuracy. Studies have shown that the impact of switching from standard IGS antenna offsets to absolute PCC, for the antennas of satellites in a local network (for baselines $<80 \mathrm{~km}$ ), on height determination $< \pm 0.5 \mathrm{~mm}$ (Chatazinikos, 2005).

At the beginning relative antenna phase center models were used within the IGS (model name: IGS_01). When the IGS gone to an absolute antenna phase center model, it also introduced a new naming format for PCC models: IGSyy.atx where yy denotes the year of the release (IGS Antenna Working Group, 2008). Because at the beginning (and even now) there were no results of absolute calibrations for all antenna types, for these antennas, absolute models were developed through the conversion from relative. Thus, at present we can speak of three models of receiver antennas and two GNSS satellites. For receiver antennas, there is:

- the relative IGS antenna phase center correction model (from relative field calibration),

- the absolute IGS antenna phase center correction model (converted from relative - all the relative antenna offsets and phase center variations that the National Geodetic Survey has computed have been added to the absolute values for AOAD/M_T antenna),

- the absolute IGS antenna phase center correction model (from absolute field calibration).

For GNSS satellites, there may be two solutions:

- the standard IGS antenna offset model,

- the absolute antenna phase center correction model.

On 17 April, 2011 the IGS introduced a new set of antenna calibrations (igs08.atx). This new set of calibrations takes into account the new robot calibrations that have been measured since the release of the igs05.atx (Baire et al., 2011). 
So far studies on switching between calibration models have been conducted mainly in large networks characterized by very long baselines and long observation sessions (Schmid et al., 2005; Völksen, 2006; Wanninger, 2009) or in networks with baselines up to $80 \mathrm{~km}$ (Chatazinikos et al., 2009). It seems that there is a lack of similar studies in local networks with shorter baselines (up to $40 \mathrm{~km}$ ) and shorter observation times (up to 1 hour).

The advantage of the absolute PCV approach is clear. Only coordinates that reflect the physics can be used in combinations with other space techniques (e.g. SLR, VLBI). The biases for different space techniques are significantly reduced when switching from relative to absolute PCVs. Unfortunately, to date not all antennas have models using absolute calibration. The main focus of this study is to determine the effect caused by switching between three receiver antennas PCV models in the ASG-EUPOS network on height determination when different receivers and antennas are used in measurements. It seems to be important for the reason that in commercial post-processing software there is often no information on what type of PCV model is used (relative, absolute converted, absolute). Meanwhile, the type of used model can significantly affect the final results. Use POZGEO-D service without such knowledge may not bring expected accuracy of results. Additionally in such networks, where the length of a static observational session usually does not exceed 1 hour, the results can visualize the impact of satellite constellations above the measured point.

\section{METHODOLOGY OF STUDIES}

While determination of the horizontal point's position using GNSS techniques (according to the requirements for different groups of precision) is generally not difficult, the accurate determination of heights causes some problems. This is due to both the high accuracy requirements for height appointment as well as specification of GNSS measurements - some error sources (e.g.: troposphere, antenna phase center variations) much more affect vertical component. It is assumed, on average, that the vertical coordinate is determined to be about 50\% less accurate than the horizontal coordinates (Parkinson and Spilker, 1996).

Analysis were done based on the observations conducted in the ASG-EUPOS network. Location of the test area is presented on figure 1.

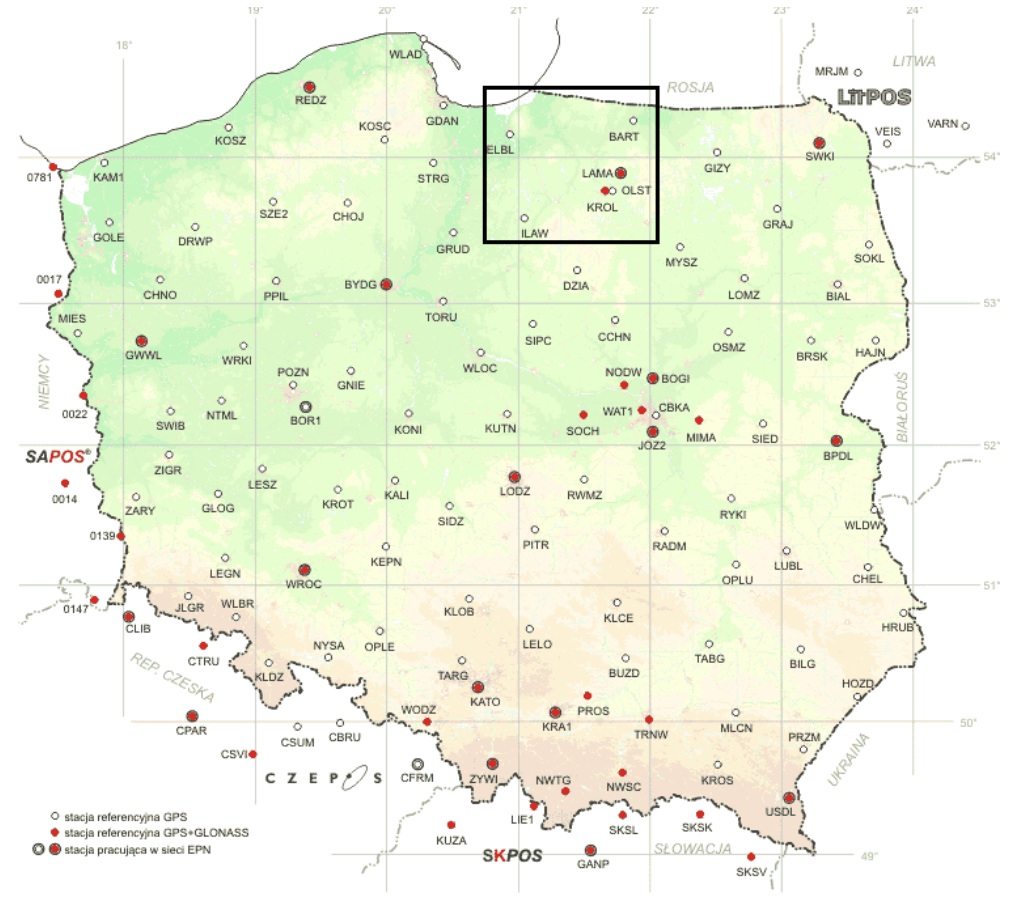

Fig.1. Location of the test area in the ASG-EUPOS network. (map: www.asgeupos.pl) 
For the analysis, four stations of the ASG-EUPOS network was selected (as reference stations two points with the most common in that network antenna models and two other as determined points) were selected. Locations of selected stations is presented on figure 2.

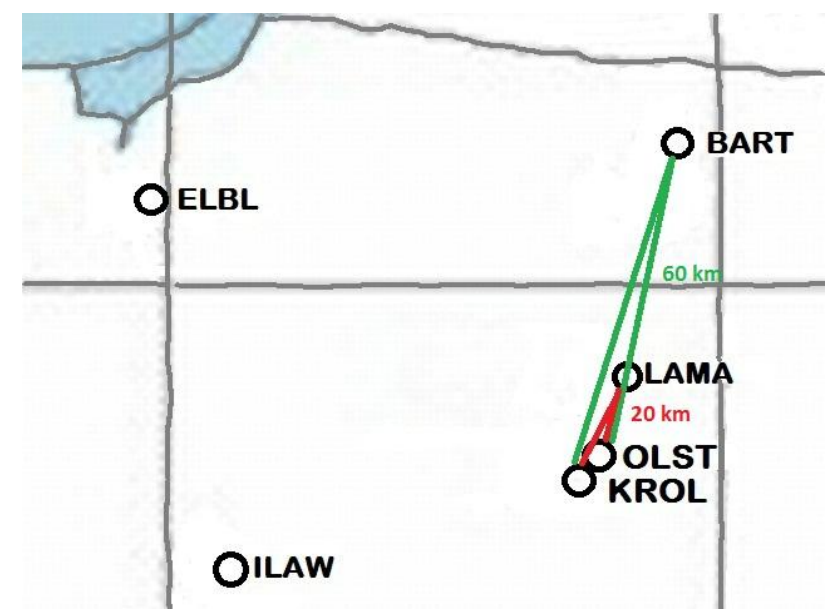

Fig.2. Location of the selected ASG-EUPOS stations.

(map: www.asgeupos.pl)

Antenna and receiver types on selected ASG-EUPOS system points are presented in table 2. As determined two points with antennas ASH701945C_M SNOW and JAVAD RINGANT G3T were selected. These antennas are rather scientific than typical surveying antennas. However, it is not difficult to find examples of surveying antennas with similar phase characteristics to those selected (e.g. JAVAD RINGANT G3T and ASH700228). Anyway the analyzes should be treated as a case study and therefore selection of antennas on the appointed points does not seem to be particularly important. It is only signaling the issue and the order of the size.

Table 2. Hardware on selected ASG-EUPOS system points

\begin{tabular}{|c|c|c|c|c|}
\hline Point name & BART & LAMA & OLST & KROL \\
\hline Antenna type & $\begin{array}{c}\text { TRM41249.00 } \\
\text { TZGD }\end{array}$ & $\begin{array}{c}\text { LEIAT 504GG } \\
\text { LEIS }\end{array}$ & $\begin{array}{c}\text { ASH701945C_M } \\
\text { SNOW }\end{array}$ & $\begin{array}{c}\text { JAVAD } \\
\text { RINGANT G3T }\end{array}$ \\
\hline $\begin{array}{c}\text { Figure of } \\
\text { antenna }\end{array}$ & Trimble NetRS & Leica & & \\
\hline $\begin{array}{c}\text { Receiver } \\
\text { type }\end{array}$ & GRX1200GG+GNSS & ASHTECH UZ-12 & JAVAD \\
\hline
\end{tabular}

(figures of antenna source: http://www.ngs.noaa.gov/ANTCAL/)

GNSS measurements of four ASG-EUPOS stations with the most common types of antennas were the basis for analysis. The selected antennas are characterized by differences between their phase characteristics and the changes in these characteristics for subsequent types of calibration. A comparison of the antenna phase characteristics on the measured points is shown in figures 3-6. 

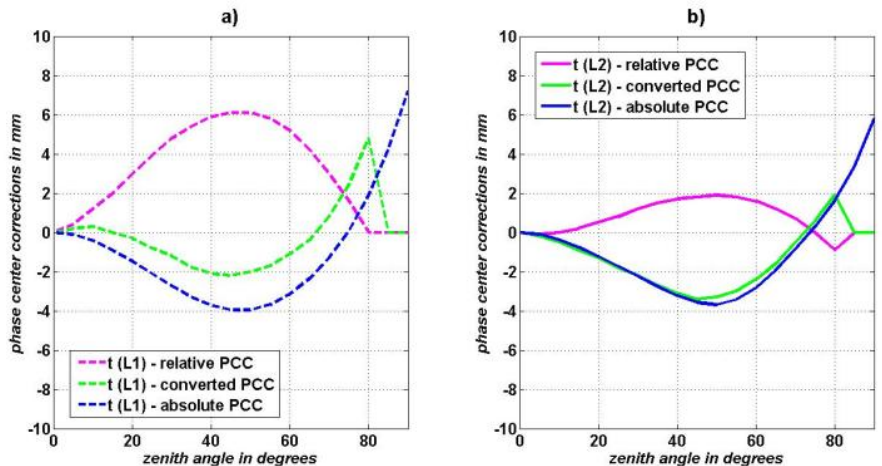

Fig. 3. IGS zenith angle dependent phase center variations for antenna TRM41249.00: a) for L1 frequency, b) for L2 frequency (source: own work).
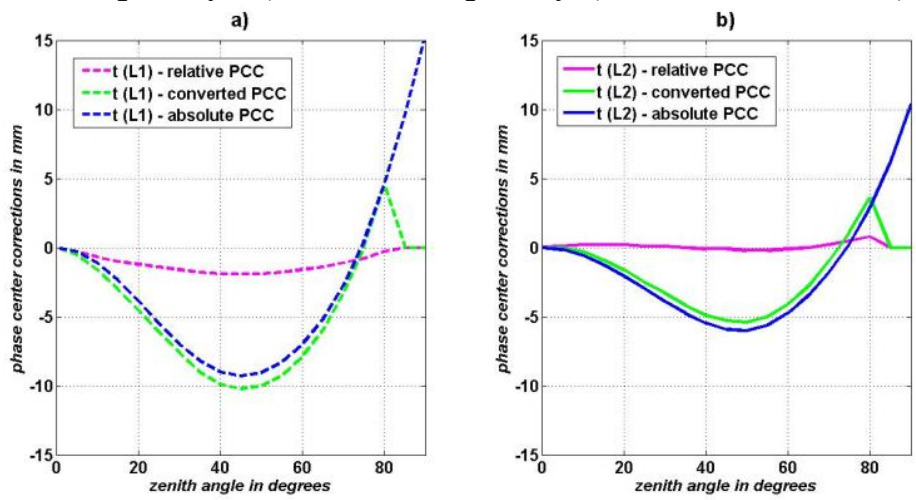

Fig. 4. IGS zenith angle dependent phase center variations for antenna LEIAT 504GG LEIS:

a) for L1 frequency, b) for L2 frequency (source: own work).
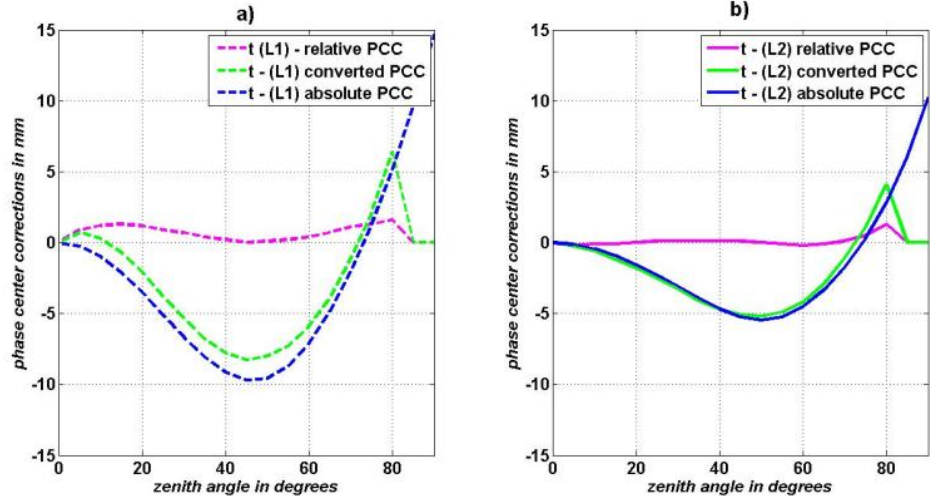

Fig. 5. IGS zenith angle dependent phase center variations for antenna ASH701945C_M SNOW: a) for L1 frequency, b) for L2 frequency (source: own work).
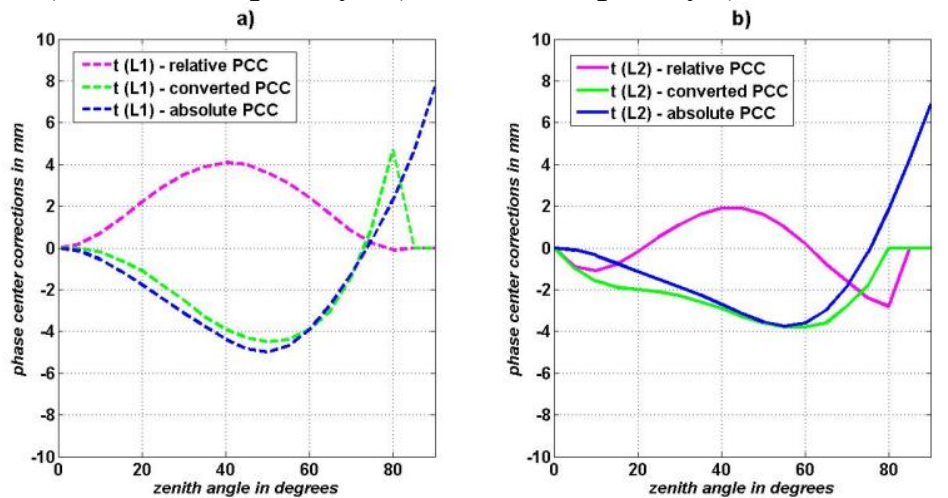

Fig. 6. IGS zenith angle dependent phase center variations for antenna JAVAD RINGANT G3T: a) for L1 frequency, b) for L2 frequency (source: own work). 
It is clear that the selected antennas have different profiles. Generally, the greatest difference was observed for medium zenith angles (from $30^{\circ}$ to $60^{\circ}$ ). These differences are also visible in comparing PCV characteristics for the same antenna, obtained from different calibration procedures (especially between relative and absolute calibration results) - the maximum differences for the same frequency are up to $10 \mathrm{~mm}$. Can be distinguished two pairs of antennas of similar PCV course: TRM41249.00 - JAVAD RINGANT G3T and LEIAT 504GG LEIS - ASH701945C_M SNOW (bold italics indicates antennas on reference points). In addition to the above figures, the L1 and L2 offsets (PCO) for the used antennas are presented (Table 3). Clear differences were also found, especially between the results of the relative and the other two calibration methods.

Table 3. Offsets for selected antennas

\begin{tabular}{|c|c|c|c|c|c|c|}
\hline \multirow{2}{*}{ Antenna type } & \multicolumn{7}{|c|}{ Offsets (PCO) [mm] } \\
\cline { 2 - 7 } & \multicolumn{2}{|c|}{$\begin{array}{c}\text { relative field } \\
\text { calibration }\end{array}$} & \multicolumn{2}{c|}{$\begin{array}{c}\text { converted from } \\
\text { relative }\end{array}$} & \multicolumn{2}{c|}{$\begin{array}{c}\text { absolute field } \\
\text { calibration }\end{array}$} \\
\cline { 2 - 7 } & $L 1$ & $L 2$ & $L 1$ & $L 2$ & $L 1$ & $L 2$ \\
\hline TRM41249.00 & 71.5 & 67.4 & 52.7 & 59.5 & 55.5 & 58.0 \\
\hline LEIAT 504GG & 106.5 & 125.4 & 87.7 & 117.5 & 88.5 & 115.3 \\
\hline ASH701945C_M & 109.3 & 126.2 & 90.5 & 118.3 & 89.9 & 119.5 \\
\hline JAV_GRANT-G3T & 69.4 & 60.6 & 50.6 & 52.7 & 50.3 & 46.9 \\
\hline
\end{tabular}

Analyses were based on three-day 24-hour observation sessions (2-4.11.2011). The following GNSS parameters were assumed for downloaded from ASG-EUPOS website observations: sampling interval $1 \mathrm{~s}$, minimum satellite elevation $10^{\circ}$. All 24-hour observations were divided into one-hour sessions and processed in a single-baseline mode. To postprocessing a commercial software enabling the introduction (definition) of PCC models themselves was used. Processing was done in three main variants (STRATEGIES):

- $\quad$ using the relative IGS models (relative field calibration);

- using absolute IGS models (converted from relative);

- using absolute IGS models (absolute field calibration).

Each "strategy' was processed using the so-called "ionosphere-free linear combination" - L3. The linear L3 combination is commonly recommended for processing baselines longer than $10 \mathrm{~km}$. When we form this combination, the ionospheric path delay is virtually eliminated. The L3 combination is the best way to mitigate the ionospheric refraction error. Using the L3 combination in our processing causes the differences in antenna PCV of both frequencies to appear in the final results. All other processing options (tropospheric model, orbits, satellite antenna calibrations, etc.) were identical in all runs. The results of calculation and their discussion are provided below.

\section{RESULTS AND ANALYSIS}

The single baseline results obtained with the TRM41249.00 TZGD antenna on a reference point and ASH701945C_M SNOW or JAVAD RINGANT G3T antennas on measured points (height differences for three previously mentioned processing strategies, on the OLST and KROL points) are presented on figure 7. This figure shows the height differences obtained from the processing of GNSS observations using absolute and relative field calibration models (absolute - relative) as well as absolute field calibration and absolute calibration converted from relative models (absolute - converted). 
a)

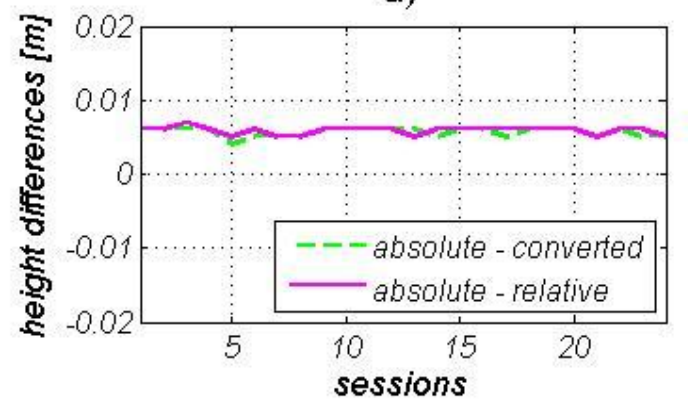

c)

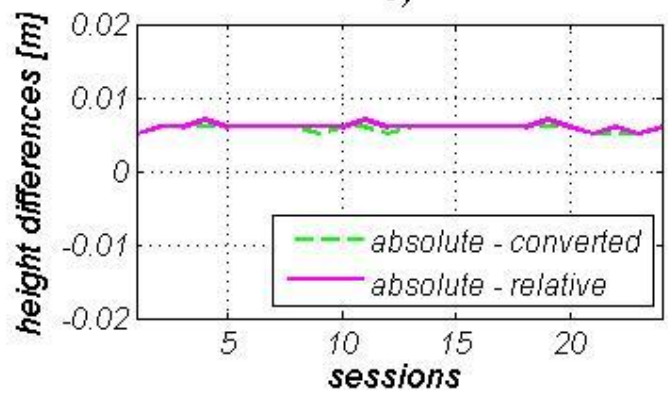

e)

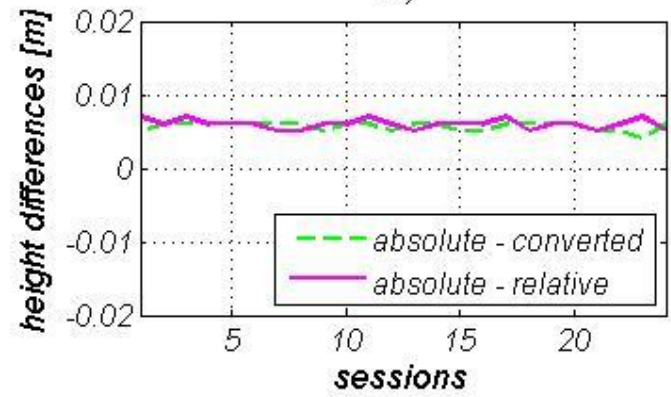

b)

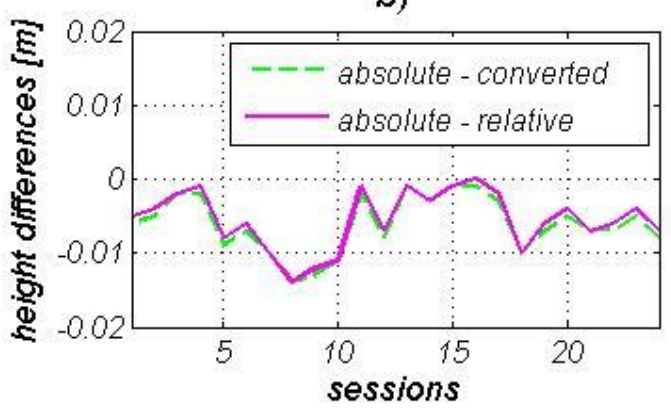

d)

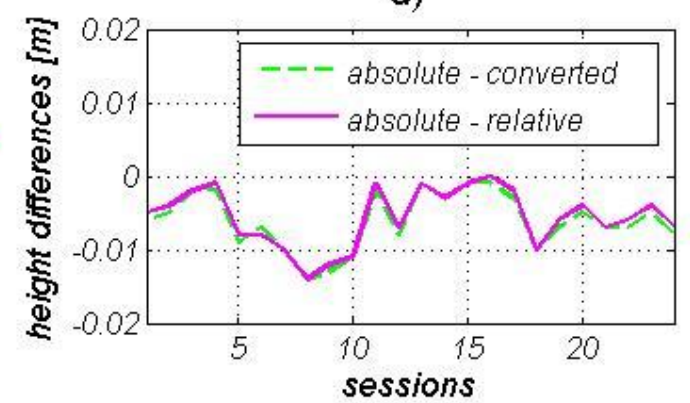

f)

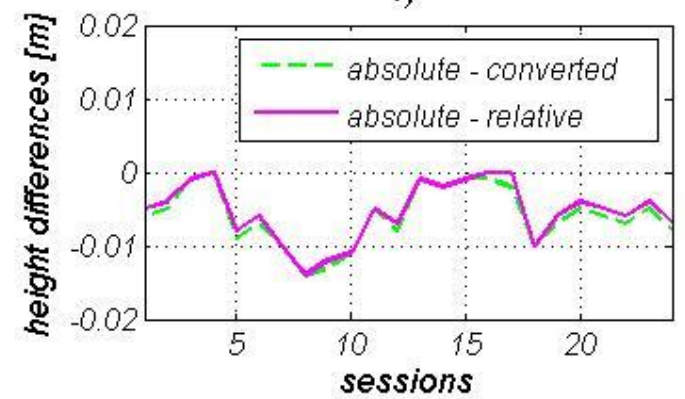

Fig. 7. The results of processing 1 hour sessions for baselines with BART as a reference point: a) day 1 - OLST point, b) day 1 -KROL point, c) day 2 - OLST point, d) day 2 KROL point, e) day 3 - OLST point, f) day 3 - KROL point.

Table 4 shows a summary of the height differences (absolute values) obtained for the baselines with TRM41249.00 TZGD antenna on a reference point and ASH701945C_M SNOW or JAVAD RINGANT G3T antennas on measured points.

Table 4. Summary of height differences obtained for the solutions with BART as a reference stations

\begin{tabular}{|c|c|c|c|c|c|c|}
\hline \multirow{2}{*}{$\begin{array}{c}\text { Post-processing } \\
\text { variants }\end{array}$} & \multicolumn{3}{|c|}{$\begin{array}{c}\text { Height differences for OLST } \\
\text { point [cm] }\end{array}$} & \multicolumn{3}{c|}{$\begin{array}{c}\text { Height differences for } \\
\text { KROL point [cm] }\end{array}$} \\
\cline { 2 - 7 } & Max. & Min. & Average & Max. & Min. & Average \\
\hline absolute - converted & 0.6 & 0.4 & 0.57 & 1.4 & 0.0 & 0.60 \\
\hline absolute - relative & 0.7 & 0.5 & 0.59 & 1.4 & 0.0 & 0.55 \\
\hline
\end{tabular}

In analyzing the results obtained for the baselines with BART as a reference point it can be seen that the height differences for OLST and KROL points have different courses but the average height difference is very similar. Larger differences were obtained for processing done using TRM41249.00 TZGD and JAVAD RINGANT G3T antennas. In comparing the height differences obtained between the solutions using the absolute and relative calibrations 
models it is clear that for some sessions its size reaches $1.4 \mathrm{~cm}$. For the variant with absolute and converted calibration models, the maximum height difference are almost identical. There is also visible a daily repeatability of the results for both baselines solutions.

The single baseline results obtained with the LEIAT 504GG LEIS antenna on a reference point and ASH701945C_M SNOW or JAVAD RINGANT G3T antennas on measured points (height differences for three previously mentioned processing strategies, on the OLST and KROL points) are presented on figure 8.

a)

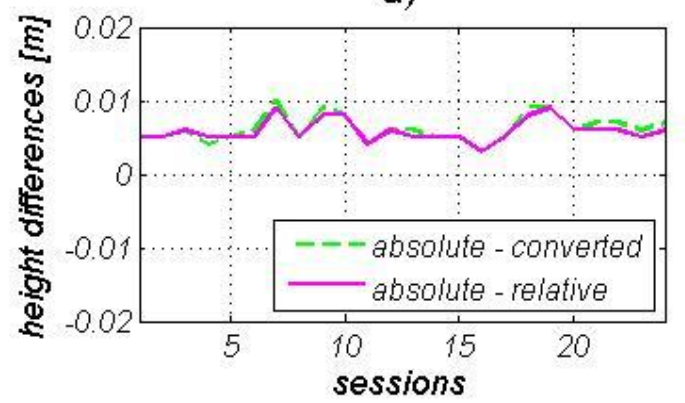

c)

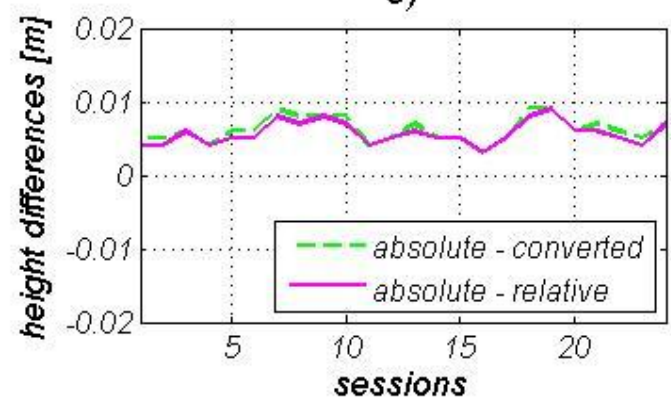

e)

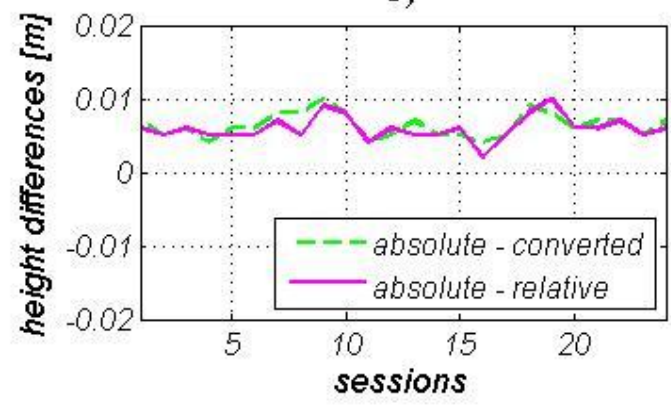

b)

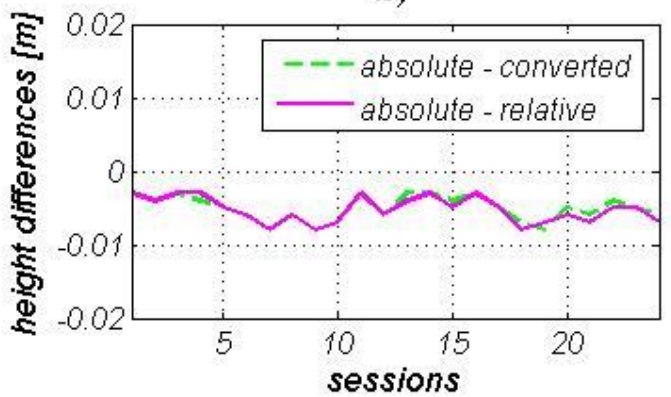

d)

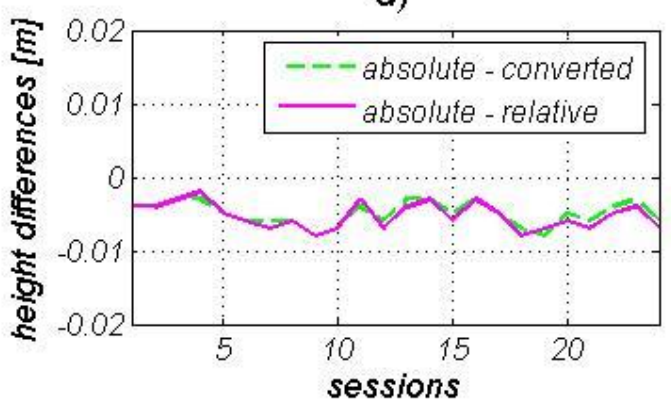

f)

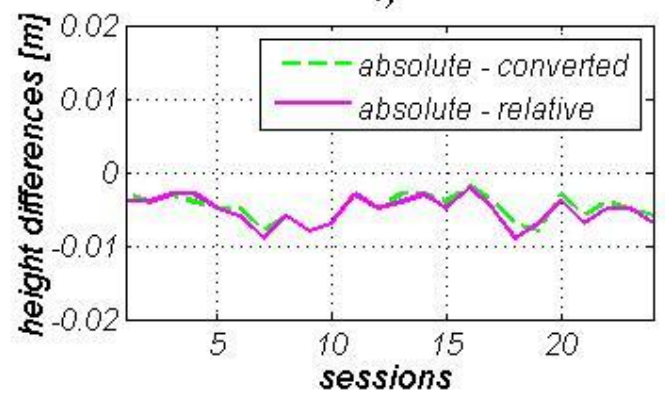

Fig. 8. The results of processing 1 hour sessions for baselines with LAMA as a reference point: a) day 1 - OLST point, b) day 1 -KROL point, c) day 2 - OLST point, d) day 2 KROL point, e) day 3 - OLST point, f) day 3 - KROL point.

Table 5 shows a summary of the height differences (absolute values) obtained for the baselines with LEIAT 504GG LEIS antenna on a reference point and ASH701945C_M SNOW or JAVAD RINGANT G3T antennas on measured points. 
Table 5. Summary of height differences obtained for the solutions with LAMA as a reference stations

\begin{tabular}{|c|c|c|c|c|c|c|}
\hline \multirow{2}{*}{$\begin{array}{c}\text { Post-processing } \\
\text { variants }\end{array}$} & \multicolumn{3}{|c|}{$\begin{array}{c}\text { Height differences for OLST } \\
\text { point [cm] }\end{array}$} & \multicolumn{3}{c|}{$\begin{array}{c}\text { Height differences for } \\
\text { KROL point [cm] }\end{array}$} \\
\cline { 2 - 7 } & Max. & Min. & Average & Max. & Min. & Average \\
\hline absolute - converted & 1.0 & 0.3 & 0.62 & 0.8 & 0.2 & 0.50 \\
\hline absolute - relative & 1.0 & 0.2 & 0.58 & 0.8 & 0.2 & 0.53 \\
\hline
\end{tabular}

In analyzing the results obtained for the baselines with LAMA as a reference point it can be seen, as previously, that the height differences for OLST and KROL points have different courses but the average height difference is very similar. A slightly larger differences were obtained for processing done using LEIAT 504GG LEIS and ASH701945C_M SNOW antennas. In comparing the height differences obtained between the solutions using the absolute and relative calibrations models it is clear that for some sessions its size reaches 1.0 $\mathrm{cm}$. For the variant with absolute and converted calibration models, the maximum height difference, as previously, are almost identical. In these solutions there is also visible a daily repeatability of the results.

Although it is a case study it can be assumed that many of the surveying antennas being characterized by similar results (size of differences).

In addition to these studies, figure 9 shows the repeatability of heights obtained for OLST and KROL points (reference point: LAMA; $20 \mathrm{~km}$ baselines; 1 hour sessions).

a)

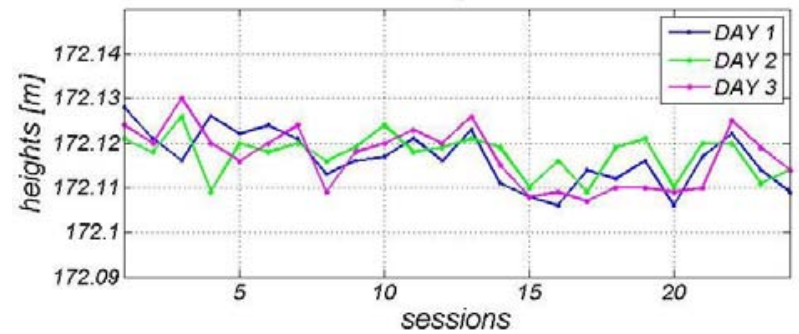

b)

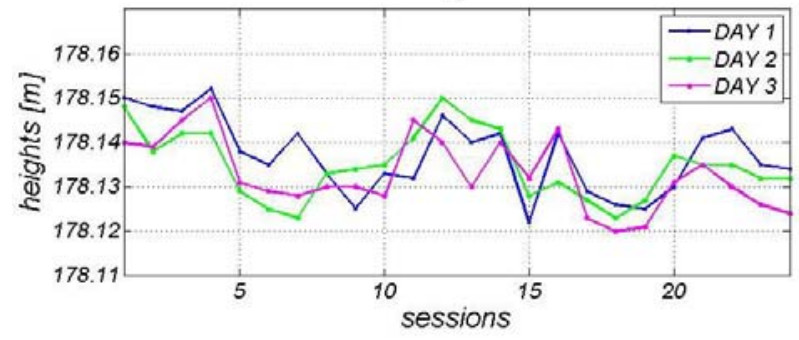

Fig 9. The repeatability of heights: a) for OLST point, b) for KROL point.

Table 6 shows a summary of results presented on figure 9 (minimum height, maximum height and standard deviation).

Table 6. Summary of height repeatability for LAMA reference point solutions.

\begin{tabular}{|c|c|c|c|c|c|c|}
\hline \multirow{2}{*}{$\begin{array}{c}\text { Day of } \\
\text { measurements }\end{array}$} & \multicolumn{3}{|c|}{ OLST } & \multicolumn{3}{c|}{ KROL } \\
\cline { 2 - 7 } & $\begin{array}{c}\mathrm{H}[\min \\
{[\mathrm{m}]}\end{array}$ & $\begin{array}{c}\mathrm{H}-\max \\
{[\mathrm{m}]}\end{array}$ & $\begin{array}{c}\text { Standard } \\
\text { deviation } \\
{[\mathrm{cm}]}\end{array}$ & $\begin{array}{c}\mathrm{H}-\min \\
{[\mathrm{m}]}\end{array}$ & $\begin{array}{c}\mathrm{H}-\max \\
{[\mathrm{m}]}\end{array}$ & $\begin{array}{c}\text { Standard } \\
\text { deviation } \\
{[\mathrm{cm}]}\end{array}$ \\
\hline DAY 1 & 178.122 & 178.152 & 0.85 & 172.114 & 172.128 & 0.61 \\
\hline DAY 2 & 178.123 & 178.142 & 0.76 & 172.109 & 172.121 & 0.47 \\
\hline DAY 3 & 178.120 & 178.150 & 0.81 & 172.107 & 172.124 & 0.67 \\
\hline
\end{tabular}


In analyzing the results presented on figure 9 and in table 6 it can be seen that contained there heights changes significantly exceed the maximum differences caused by PCC model conversion.

It is clear that the effect of switching between calibration models on the results of the doublefrequency observation processing can reaches or exceeds $1 \mathrm{~cm}$. Taking into account however the low repeatability of results of the 1-hour session, it seems that this effect is not to neglect mainly in high accuracy applications.

\section{CONCLUSIONS}

In this study, the height differences caused by using different calibration models in processing GNSS observations from POZGEO-D service of ASG-EUPOS system were compared. The analysis was conducted using 3 days of GNSS data, collected with four different receivers and antennas, divided into one hour observation sessions.

The update of receiver antenna calibrations from relative to absolute in our study (using observations from four ASG-EUPOS stations with two the most popular antennas in the network as reference stations, in combination with observations done using ASH701945C_M SNOW or JAVAD RINGANT G3T antennas) induces a jump (depending on the measurement session) in the vertical component to $1.4 \mathrm{~cm}$ in $\mathrm{L} 3$ solutions.

Switching from absolute converted to absolute antenna PCV models gave very similar results as the conversion from relative to absolute. May be it would be worth checking results obtained from a mixing solution (e.g. absolute converted model for one antenna and absolute for other).

The analysis also showed that the satellite constellation above the measured point has a significant impact on the final results (in one case changes in height differences from 0 to 1.4 $\mathrm{cm}$ were obtained, depending on the time of measurement).

The final analysis related to repeatability of heights obtained from one-hour sessions (20 $\mathrm{km}$ baselines) show relatively low accuracy compared to differences caused by PCC model conversion. It can be concluded, that although this effect may have a visible effect on height determination, however it should be taken into account mainly in high accuracy applications.

\section{REFERENCES}

Baire, O., Pottiaux, E., Bruyninx, C., Defraigne, P., Legrand, J., Bergoet, N. (2011). Comparison of Receiver Antenna Calibration Models used in the EPN. http://www.euref.eu/symposia/2011Chisinau/Symposium2011-Chisinau.html.

Braun, J., Rocken, C., Meertens, C. M., Johanson, J. (1993). GPS antenna mixing and phase center corrections. Eos Trans. AGU, Fall Meeting Supplement: 197.

Bosy, J., Oruba, A., Graszka, W., Leończyk, M., Ryczywolski, M. (2008). ASG-EUPOS densification of EUREF Permanent Network on the territory of Poland. Reports on Geodesy, 2 (85): 105-112.

Chatazinikos, M., Fotiou, A., Pikradis, C. (2009). The effects of the receiver and satellite antenna phase center models on local and regional GPS networks. Proceedings of the International Symposium "Modern technologies, educations and professional practice in geodesy and relative fields". Sofia, 5-6 November.

Dawidowicz K. (2011). Comparison of using relative and absolute PCV corrections in short baseline GNSS observation processing. Artificial Satellites, Vol.46: 19-31. 
Falko, M., Seeber, G., Völksen, Ch., Wübbena, G., Schmitz, M. (1998). Results of Absolute Field Calibration of GPS Antenna PCV. ION GPS-98; Proceedings of the 11th International Technical Meeting of the Satellite Division of the Institute of Navigation, Nashville, TN; UNITED STATES; 15-18 Sept.: 31-38.

Figurski, M., Kamiński, P., Kroszczyński, K., Szafranek, K. (2009). ASG-EUPOS monitoring with reference to EPN, Artificial Satellites, Vol. 44: 85-94.

Geiger, A. (1998). Modeling of Phase Center Variation and its Influence on GPS Positioning. GPS-Techniques Applied to Geodesy and Surveying: Proceedings of the International GPS-Workshop Darmstadt, April 10 to 13, Editor: Erwin Groten, Robert Strauß, Lecture Notes in Earth Sciences, vol. 19: 210-222.

Gürres, B., Campbell, M., Becker, M., Siemes, M. (2006). Absolute calibration of GPS antennas: Laboratory results and comparison with field and robot techniques, GPS solutions, 10: 136-145.

IGS Working Group. (2008). IGS antenna files. ftp://igscb.jpl.nasa.gov/pub/station/genereal/ antenna_README.pdf.

Mader, G. L. (1999). GPS Antenna Calibration at the National Geodetic Survey. GPS Solutions, Vol 3(1): 50-58.

Parkinson, B. W., Spilker, J. J. (1996). Global Positioning System: Theory and Applications Vol I, American Institute of Aeronautics and Astronautics, Inc. 370 L'Enfent Promenade, SW, USA, Washington. 775 pages.

Rothacher, M. (2001). Comparison of Absolute and Relative Antenna Phase Center Variations. GPS Solutions, Vol. 4: 55-60.

Rothacher, M., Mader, G. (1996). Combination of antenna phase center offsets and variation: antenna calibration set IGS_01, anonymous ftp ubeclu.unibe.ch, June.

Rocken, C. (1992). GPS antenna mixing problems. UNAVACO Memo, November 12.

Schmid, R., Rotchaher, M. (2003). Estimation of elevation-dependent satellite antenna phase center variations of GPS satellites. Journal of Geodesy, Vol. 77: 440-446.

Schmid, R., Rothacher, M., Thaller, D., Steigenberger, P. (2005). Absolute phase center corrections of satellite and receiver antennas. GPS Solutions, Volume 9, Number 4: 283293.

Schmid, R., Steingerberg, P., Rotchacher, M. (2005). Benefits from absolute GPS antenna phase center modeling. Advances in GPS Data Processing and Modelling, London 9-10 November (www.espace-tum.de/mediadb/15354/15355/Vortrag_London.pdf).

Schmid, R., Steingerberg, P., Gendt, G., Ge, M., Rotchacher, M. (2007). Generation of a consistent absolute phase center corrections model for GPS receiver and satellite antennas. Journal of Geodesy, Vol. 81: 781-798.

Snay, R. A., Soler, T. (2008). Continuously Operating reference Station (CORS): History, Applications and Future Enhancements, Journal of Surveying Engineering, November 2008: 95-104.

Völksen, Ch. (2006). The Impact of different GPS Antenna Calibration Models on the EUREF Permanent Network, Report on the Symposium of the IAG Sub-commission for Europe (EUREF), mitteilungen des BKG, Band 38, Verlag des BKG, Frankfurt/Main: 7378. 
Wanninger, L. (2009). Correction of apparent position shifts caused by GNSS antenna changes, GPS Solutions, No 13: 133-139.

Zeimetz, P., Kuhlman, H. (2008). On the Accuracy of Absolute GNSS Antenna Calibration and the Conception of a New Anechoic Chamber, FIG Working Week 2008, Stockholm, Sweden 14-19 June.

Zhu, S. Y., Massmann, F. H., Yu, Y., Reigber, Ch. (2003). Satellite antenna phase center offsets and scale errors in GPS solutions. Journal of Geodesy, Vol. 77, No. 11-12: 668672.

Received: 2012-09-04,

Reviewed: 2012-11-13, by Z. Siejka,

Accepted: 2012-11-14. 